\title{
Growth and characterization of $\mathrm{Hg}_{1-x} \mathrm{Cd}_{x} \mathrm{Te}$ epitaxial films by isothermal vapour phase epitaxy (ISOVPE)
}

\author{
MANJU MALHOTRA, MADHUKAR GAUTAM, J K RADHAKRISHNAN, \\ VINOD KAPOOR, SUDEEP VERMA, UPENDRA KUMAR, ANAND KUMAR, \\ GARIMA GUPTA, ANSHU GOYAL and S SITHARAMAN* \\ Solid State Physics Laboratory, Lucknow Road, Delhi 110 054, India
}

MS received 20 September 2004; revised 5 February 2005

\begin{abstract}
Growth of $\mathrm{Hg}_{1-x} \mathrm{Cd}_{x} \mathrm{Te}$ epitaxial films by a new technique called asymmetric vapour phase epitaxy (ASVPE) has been carried out on CdTe and CZT substrates. The critical problems faced in normal vapour phase epitaxy technique like poor surface morphology, composition gradient and dislocation multiplication have been successfully solved. The epitaxial films have been electrically characterized by using the Hall effect and capacitance-voltage $(C-V)$ measurements.
\end{abstract}

Keywords. MCT; epitaxy; characterization; vapour phase.

\section{Introduction}

The ternary II-VI semiconductor, $\mathrm{Hg}_{1-x} \mathrm{Cd}_{x} \mathrm{Te}$ (MCT), is an important intrinsic alloy material for use as infrared (IR) detector in thermal imaging applications. Its bandgap can be tuned by varying the value of $x$ from 0 to 1 and hence detectors with peak responses in the two atmospheric transmission windows, $3-5 \mu \mathrm{m}$ and $8-14 \mu \mathrm{m}$, can be produced. Further, the outstanding fundamental properties of MCT, e.g. high optical absorption coefficient, high electron mobility, low thermal carrier generation rate and tunable bandgap, make it an excellent material for infrared detectors (Elliot et al 1994). During the past 2-3 decades, these alloys have found widespread applications as infrared detectors for military, space and industrial systems.

Several bulk and epitaxial growth techniques have been developed to obtain MCT single crystals. Among the epitaxial techniques, molecular beam epitaxy (MBE), metallo-organic chemical vapour deposition (MOCVD), liquid phase epitaxy (LPE) and isothermal vapour phase epitaxy (ISOVPE) are the most commonly used worldwide. The ISOVPE technique has distinct advantages of producing MCT epitaxial films with good radial compositional uniformity, surface morphology and electrical properties. Moreover, it is a low cost, simple and versatile technique (Adamiec and Miroslaw 1998). Different variations of ISOVPE in open tube (Shin and Pasko 1984; Piotrowski et al 1987) and closed tube (Bailly et al 1975; Becla et al 1982a) configurations have been utilized by different researchers. The major emphasis is on controlling a number of growth parameters viz. temperature, source

*Author for correspondence (SITHARAMAN/SSPL@ ssplnet.org) to substrate distance, time and mercury partial pressure. High capability quasi-closed system have also been used for the growth of device quality epitaxial films of MCT (Piotrowski and Nowak 1988). However, the ISOVPE technique on CZT or CdTe substrates suffers from an inherent disadvantage of composition gradient across the thickness of the film. In this paper, we have tried to overcome the above mentioned critical problems by setting up a new technique called asymmetric vapour phase epitaxy (ASVPE).

\section{Experimental}

Asymmetric vapour phase epitaxy (ASVPE) was carried out under isothermal conditions in a sealed quartz ampoule. There are three main conditions to be fulfilled compared to the experiments conducted in symmetric conditions. The substrate and the ampoule (figure 1) are tilted by 45 degrees which gives rise to parallel line of vapour flow from one end to the other end of substrate. The substrate is placed on the grooves cut in a quartz plug and the top portion of the substrate is covered with a highly polished sapphire plate. The vapours diffuse in the minute gap between the substrate and sapphire plate and hence direct attack of vapours is avoided. The free volume available above the source has to be optimized with respect to the diameter of the quartz ampoule to ensure uniform flux density throughout the substrate area. For example, in our case, quartz ampoule having a diameter of $18 \mathrm{~mm}$ and free volume of $65 \mathrm{cc}$ was provided. The substrates used were properly prepared for their surface by mechanical as well as chemomechanical polishing in $1 \% \mathrm{Br}_{2}$ and $\mathrm{CH}_{3} \mathrm{OH}$ solution. The starting material (charge) for the growth of the films was pre-synthesized $\mathrm{HgTe}$ prepared from $7 \mathrm{~N} \mathrm{Hg}$ and $6 \mathrm{~N}^{+}$ 
Te starting raw materials. The HgTe was powdered and saturated with Te in 9/1 molar ratio to be used as charge for the growth experiments. The substrate was placed at distances varying from 6 to $15 \mathrm{~mm}$ above the charge and sealing was done under high vacuum. The experimental arrangement is shown schematically in figure 1. As shown in the figure the substrate to source distance was not same throughout and the free volume above the source was chosen in such a way that the vapour flux available for diffusion in both the distances, $d_{\min }$ and $d_{\max }$, were the same. Also since the vapours have to pass through the minute gap between the sapphire plate and the substrate for the growth to take place the direct attack of tellurium vapours was minimized resulting in excellent terracing morphology characteristic of LPE grown films. Also the source material was taken in separate bulb at the end of the ampoule which was separated by the rest of the ampoule by a narrow cavity which completely avoids the contact of the source material with the substrate allowing only the vapours to react with the $\mathrm{Cd}_{0.96} \mathrm{Zn}_{0.04} \mathrm{Te} / \mathrm{CdTe}$ substrate. The growth was carried out keeping the mercury pressure in the system within the existing region of solid $\mathrm{HgTe}$ so that the dissociated Te vapours controlled the growth rate.

The growth mechanism is as follows: The deposition takes place in four major steps: (i) dissociative evaporation of the $\mathrm{HgTe}$ source, (ii) transport of $\mathrm{Hg}$ atoms and $\mathrm{Te}_{2}$ molecules from the source to the substrate, (iii) formation of $\mathrm{HgCdTe}$ at the surface of the growing layer and (iv) interdiffusion of components in the layer. The addition of Te allows control of the mercury pressure for growth. The ampoule is heated in a furnace in asymmetric condition where substrate and charge are tilted by $45^{\circ}$. Different

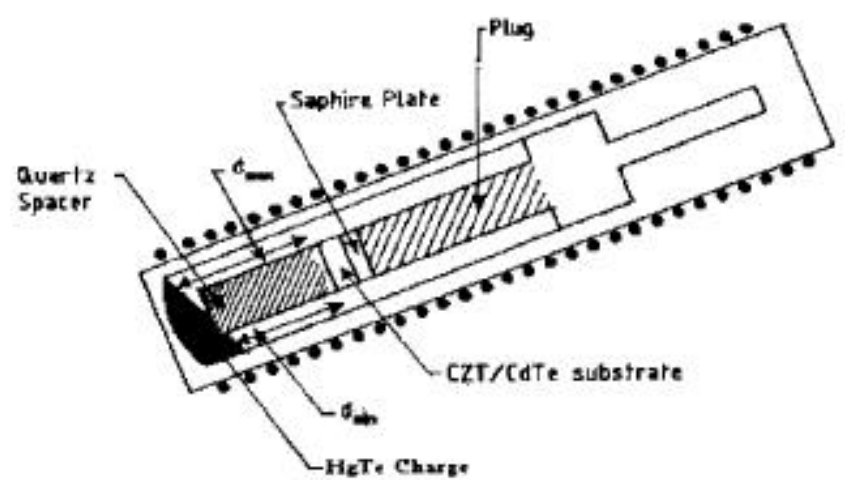

Figure 1. Schematic diagram of experimental arrangement for asymmetric vapour phase epitaxy (ASVPE). substrate temperatures ranging from $470-600^{\circ} \mathrm{C}$ and growth durations were used. The films were characterized for their surface morphology by optical microscope and SEM. The composition variation along the thickness was measured by EDAX attachment (ISIS 200 EDS System) with SEM. FTIR transmission measurements were done on BIO RAD (FTS-40) for the composition as well as thickness measurement of the films. The crystalline quality of the films was analysed by high resolution rocking curve (DCRC Phillips PW3040/60) X-ray diffraction method using $\mathrm{CuK}_{\alpha}$ radiation.

\section{Control of thickness}

In our experiments we have tried to control the thickness by changing the amount of HgTe source taken, time allowed for the diffusion to take place and the temperature of growth. We were able to grow $12-100 \mu \mathrm{m}$ thick epilayers with sharp interface. Table 1 shows the thickness of the epilayers grown at different temperatures keeping the amount of initial HgTe charge taken and the time of growth, same.

The table below shows that though initial $\mathrm{HgTe} / \mathrm{Te}$ ratio is approximately same in both the experiments, the higher temperature of growth resulted in higher thickness. The reason being the tellurium diffusion becomes faster at high temperatures which is the key mechanism for the growth of high thickness epitaxial film. The growth rate on CdTe substrates is found to be twice that on $\mathrm{Cd}_{0.96} \mathrm{Zn}_{0.04} \mathrm{Te}$ substrates signifying that the tellurium diffusion coefficient on these two substrates are entirely different and the diffusion rate goes down in $\mathrm{Cd}_{0.96} \mathrm{Zn}_{0.04} \mathrm{Te}$ substrates. Table 2 shows the experimental details of growth on CdTe and CZT substrates.

We have measured the thickness of the epilayers grown on the direct Te vapour exposure side as well as the unexposed side of the substrate from cross-section measurement of the cleaved section in scanning electron microscope and found that thick layers can be grown on the exposed side whereas thin layers can be grown on unexposed side (table 3).

Hence, by controlling various parameters, we are able to control the thickness of the grown epitaxial layers from $12-100 \mu \mathrm{m}$. So, for growth of about $30 \mu \mathrm{m}$ film on the unexposed side of the substrate, a minimum of $20 \mathrm{~h}$ growth is necessary for CdTe substrates whereas a minimum of $40 \mathrm{~h}$ growth is necessary for $\mathrm{Cd}_{0.96} \mathrm{Zn}_{0.04}$ Te substrates using

Table 1. Variation of thickness of MCT films with growth temperature.

\begin{tabular}{llccc}
\hline Sample no. & $\begin{array}{c}\text { Amount of charge } \\
(\mathrm{g})\end{array}$ & $\begin{array}{c}\text { Temperature of growth } \\
\left({ }^{\circ} \mathrm{C}\right)\end{array}$ & $\begin{array}{c}\text { Time of growth } \\
(\mathrm{h})\end{array}$ & $\begin{array}{c}\text { Thickness } \\
(\mu \mathrm{m})\end{array}$ \\
\hline VPE12 & HgTe $5 \cdot 7+\mathrm{Te} 0 \cdot 8$ & 590 & 43 & 100 \\
VPE19 & HgTe $4 \cdot 95+\mathrm{Te} 0 \cdot 5$ & 485 & 43 & 60 \\
\hline
\end{tabular}


our experimental set up. The growth rate observed in our experimental set up is of the order of $1 \cdot 5-2 \mu \mathrm{m} / \mathrm{h}$ on CdTe substrates and about $0 \cdot 6-1 \mu \mathrm{m} / \mathrm{h}$ on $\mathrm{Cd}_{0.96} \mathrm{Zn}_{0.04} \mathrm{Te}$ substrates which are comparable with the values reported by other workers using ISOVPE (Fleming and Stevanson 1987).

\section{Composition control}

In our work, we have found that the ultimate composition of the MCT epilayer can be controlled by the time of growth after standardizing the partial pressure of $\mathrm{Hg}$ and Te inside the free volume between the substrate and the source. This eliminates different $\mathrm{Hg}$ partial pressures to be employed for different distances between the source and the substrate (Tufte and Stelzer 1969; Becla et al 1982b). Higher time of growth results in lower $x$ values of $\mathrm{Hg}_{1-x} \mathrm{Cd}_{x} \mathrm{Te}$ since the availability of $\mathrm{Cd}$ from the bulk of the substrate for reaction with the HgTe vapours at the surface is depleted as the time progresses. As shown in figure 2, the composition of the epitaxial layers can be tuned by controlling the growth time alone. Lower growth time results in higher surface composition and the subsequent interdiffusion between the bulk and the surface of the epitaxial film during cooling ends to comparatively higher $x$ value. Composition $(x)$ of the epitaxial layer was calculated from $50 \%$ transmission cutoff wavenumber using the standard formula (Hansen et al 1982).

By controlling various parameters e.g. mercury and tellurium partial pressure from the source, substrate temperature, source to substrate distance and time of growth, we were able to control the thickness of the grown epitaxial layers from $12-100 \mu \mathrm{m}$ with sharp interface. However,

Table 2. Thickness variation of epitaxial film with time of growth.

\begin{tabular}{lcccc}
\hline $\begin{array}{l}\text { Sample } \\
\text { no. }\end{array}$ & Substrate & $\begin{array}{c}\text { Temperature of } \\
\text { growth }\left({ }^{\circ} \mathrm{C}\right)\end{array}$ & $\begin{array}{c}\text { Time } \\
(\mathrm{h})\end{array}$ & $\begin{array}{c}\text { Thickness } \\
(\mu \mathrm{m})\end{array}$ \\
\hline VPE17 & CZT & 540 & 18 & Few $\mu \mathrm{m}$ \\
VPE18 & CZT & 526 & 45 & 40 \\
VPE28 & CZT & 520 & 45 & 46 \\
VPE14 & CdTe & 510 & 18 & 35 \\
VPE22 & CdTe & 530 & 31 & 55 \\
VPE25 & CdTe & 530 & 16 & 25 \\
\hline
\end{tabular}

Table 3. Thickness of epitaxial films on two sides of substrate.

\begin{tabular}{lcc}
\hline Sample no. & $\begin{array}{c}\text { Thickness on } \\
\text { exposed side }(\mu \mathrm{m})\end{array}$ & $\begin{array}{c}\text { Thickness on } \\
\text { unexposed side }(\mu \mathrm{m})\end{array}$ \\
\hline VPE19 & 60 & 12 \\
VPE28 & 46 & 32 \\
\hline
\end{tabular}

the growth rate of $\sim 1.5 \mu \mathrm{m} / \mathrm{h}$ was obtained on CdTe substrates whereas growth rate of $\sim 0.75 \mu \mathrm{m} / \mathrm{h}$ was obtained on CZT substrates. This is due to the fact that under the same mercury and tellurium partial pressures in the source, the out diffusion of Cd from CZT substrate is reduced due to the presence of $\mathrm{Zn}$.

Various source materials were used e.g. HgTe, HgTe and $\mathrm{Te}, \mathrm{HgTe}$ and $\mathrm{CdTe}$ and surface morphology and composition gradient were studied. Best results were obtained in case of HgTe and CdTe as source material. In this case, growth resulted in 60 micron thick layer with composition gradient of the order of $0 \cdot 003 / \mu \mathrm{m}$. As shown in figure 3 the transmission spectrum slope is comparatively sharper and the depth gradient has also been verified by differential chemical etching method. This depth gradient obtained is comparable with LPE grown layers (Norton and Erwin 1989).
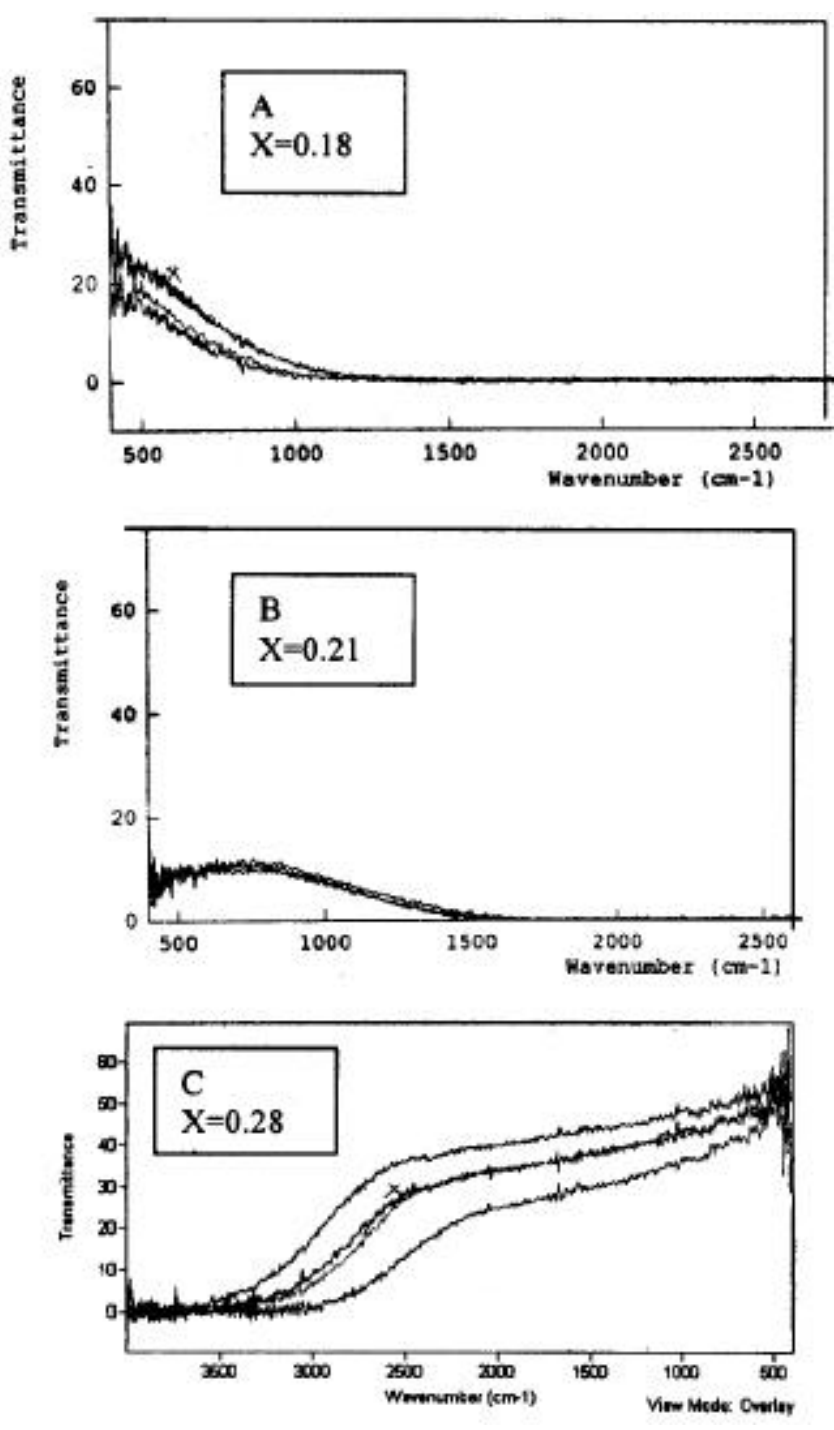

Figure 2. FTIR spectra of MCT epilayers grown for (A) $27 \mathrm{~h}$, (B) $21 \mathrm{~h}$ and (C) $18 \mathrm{~h}$. 


\section{Surface morphology}

The surface morphology of the epilayers were found to be smooth and void-free. The films, in general, showed typical terracing pattern of epitaxial films grown on slightly misoriented substrates $\left(111 \pm 0 \cdot 5^{\circ}\right)$ as shown in figure 4. It was observed that irrespective of A or B face of the substrate, the unexposed side resulted in the smoother surface morphology as compared to the exposed side. This is expected to be due to reduced tellurium and cadmium vapour attack on the unexposed side. On the exposed side of the substrate, the tellurium and cadmium vapours are seen to decorate various dislocations of the CZT substrate during the epitaxial layer growth as shown in figure 5 .

This effect has been observed by others also (Bagai et al 1991), but in our case, we are able to decorate all kinds of defects. Figure 5a shows the decoration of cellular structure whereas figure $5 \mathrm{~b}$ shows the decoration of grain boundaries. Figures $5 \mathrm{c} \& \mathrm{~d}$ show the decoration of microprecipitates.

\section{Annealing}

In general, as grown films of MCT are $p$-type with carrier concentration of $5 \times 10^{16}-1 \times 10^{17} \mathrm{~cm}^{-3}$ and the mobility

vpe 29-3

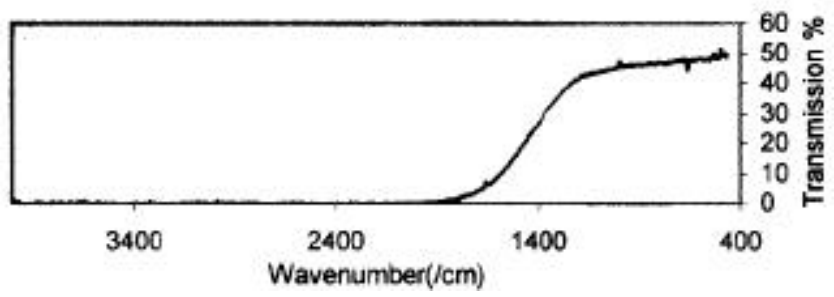

Figure 3. FTIR spectrum of $\mathrm{Hg}_{0.8} \mathrm{Cd}_{0.2} \mathrm{Te}$ epitaxial film using ASVPE technique and source of HgTe and CdTe.

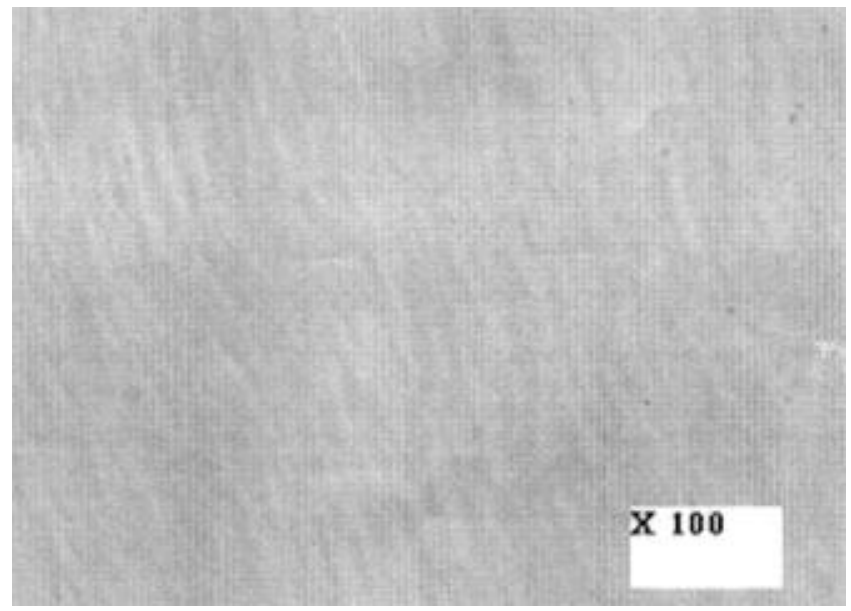

Figure 4. Surface morphology of as grown $\mathrm{Hg}_{0.8} \mathrm{Cd}_{0.2} \mathrm{Te}$ epitaxial film. $\sim 150-200 \mathrm{~cm}^{2} / \mathrm{V}$-s. Normally, these films are subjected to low temperature annealing in mercury atmosphere in a sealed ampoule to reduce the mercury vacancy concentration (Takigawa et al 1988). At the same time, the mercury annealing enhances the defect density in the films due to dislocations being multiplied around the tellurium precipitates (Schaake and Tregilgas 1983). Due to high growth temperature $\left(>500^{\circ} \mathrm{C}\right)$ in VPE process, the tellurium precipitate formation is unavoidable. To overcome this problem, we have utilized the dislocation multiplication reduction (DMR) process (Chandra et al 1991) in which high temperature preanneal is carried out before subjecting the films to low temperature anneal. As shown in figure $6 \mathrm{a}$, the as grown layers show IR transmission of $\sim 35 \%$ which increases to $\sim 45 \%$ (figure $6 \mathrm{~b}$ ) due to the annihilation of tellurium precipitates, responsible for absorption. In addition to this, the spatial uniformity of the composition is found to be improved on annealing. This can be explained as follows. During the high temperature annealing, the in-diffusing $\mathrm{Hg}$ vapours annihilate the tellurium precipitates, forming $\mathrm{HgTe}$ complexes which, in turn, further diffuse into the bulk of the film and a rearrangement of composition takes place. Also, it can be observed from figure 7 that CZT/MCT interface is sharp and epilayer is defect-free up to $10 \mu \mathrm{m}$ (in between two arrows marked) indicating that the accumulated Te precipitates have moved away from the interface to the surface on annealing. The interference fringes obtained in the FTIR transmission spectrum after annealing also reflects the fact that the CZT/ MCT interface crystalline quality has improved.

MCT epitaxial layers were non destructively evaluated using high resolution X-ray diffractometer before and after DMR annealing process. As it can be seen from figures $8 \mathrm{a}$ and $\mathrm{b}$, the crystalline quality of the MCT epitaxial film has improved after the DMR annealing process as re-
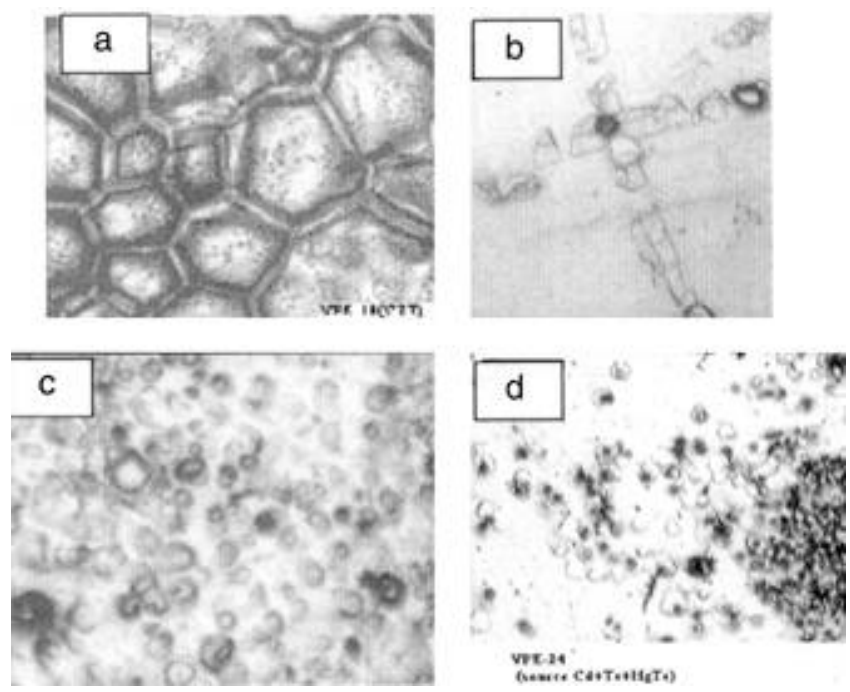

Figure 5. Decoration of dislocations during VPE growth by tellurium and cadmium vapours. 
flected in the X-ray rocking curve measurements. The double peaks which were predominantly visible in the X-ray rocking curve before annealing have been smoothened after the annealing and the overall FWHM values have reduced considerably from 140 arc s -80 arc s with large increase in X-ray intensity counts. The corresponding etch pit density (EPD) values as determined by everson etchant have reduced from $10^{6} / \mathrm{cm}^{2}$ to $10^{5} / \mathrm{cm}^{2}$ after the DMR annealing process.

These defect density and rocking curve values obtained are comparable with the values obtained in other techniques like LPE, MOCVD (Lu et al 1983; Chandra et al 1991).
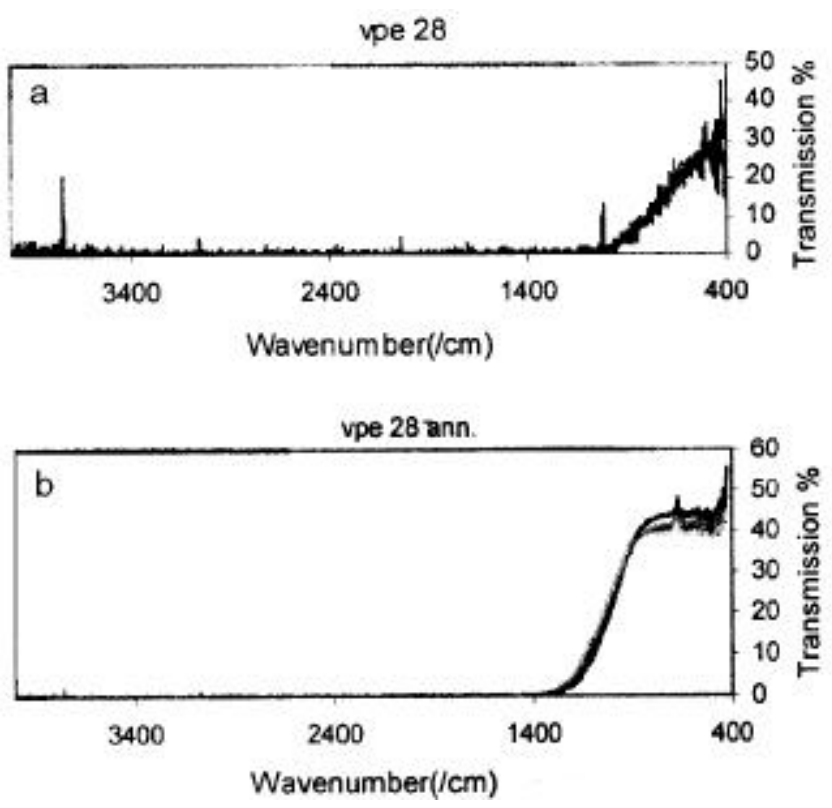

Figure 6. a. FTIR spectrum of as grown MCT film and b. FTIR spectrum of MCT film after the two-step DMR annealing.

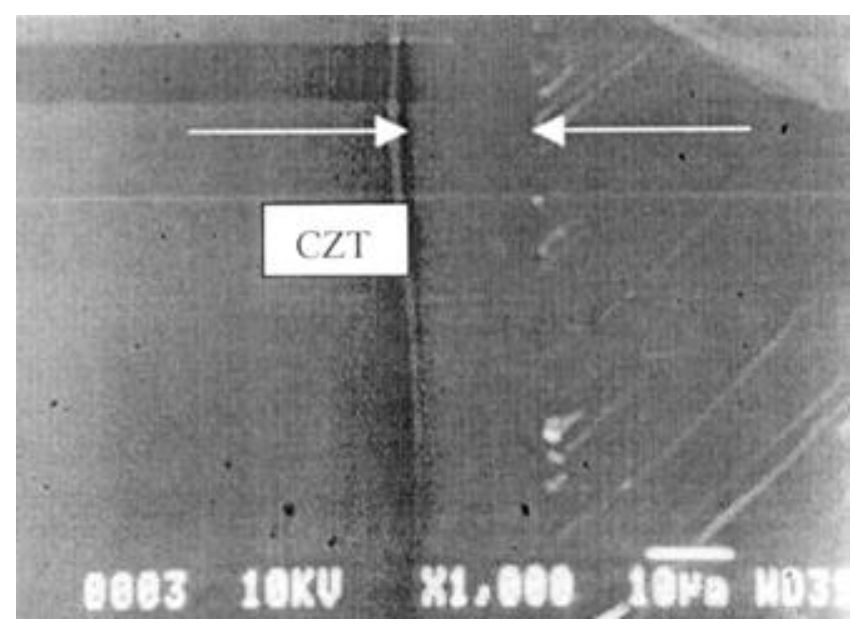

Figure 7. SEM picture of CZT/MCT interface after DMR annealing.

\section{Electrical properties}

As grown MCT epilayers were $p$-type with carrier concentration of the order of $1 \times 10^{17} / \mathrm{cm}^{3}$ having mobility of the order of $200 \mathrm{~cm}^{2} / \mathrm{v}$-s. These $p$-type layers were subjected to mercury annealing at $200^{\circ} \mathrm{C}$ for $24 \mathrm{~h}$ to convert them to $n$-type films. To understand the compensation mechanism present in the films, variable temperature Hall measurements were carried out on these $n$-type epilayers from room temperature to $10 \mathrm{~K}$ (figure 9). The carrier concentration varied from $10^{15}$ to $10^{16} / \mathrm{cm}^{3}$ with temperature and the maximum mobility obtained was $5 \times$ $10^{4} \mathrm{~cm}^{2} / \mathrm{v}$-s. From the logarithmic plot, the activation energy was found to be $\sim 0.004291 \mathrm{eV}$. For most of the II-VI compound semiconductors impurity activation energies are $>0 \cdot 15 \mathrm{eV}$ (Bube 1960). This low activation energy $(4 \mathrm{meV})$ close to zero obtained in our epitaxial layers suggests that the layer is compensated with intrinsic defects only and do not have any deep level impurity centre for compensation.

Metal insulator semiconductor (MIS) diodes were fabricated on the VPE grown MCT epitaxial films. The surface of the epitaxial layers were chemically prepared using bromine in methanol solution and loaded into the vacuum evaporation chamber for depositing $1000 \AA$ thick $\mathrm{ZnS}$ film using photolithographic mask. Au contacts of $50 \mu \mathrm{m}$ diameter were deposited by thermal evaporation. $\mathrm{ZnS}$ film was etched from one corner for enabling the electrical contact to be taken from MCT film. The capacitancevoltage $(C-V)$ measurements were carried out using Boonton Capacitance Meter (Model 7200) in the voltage

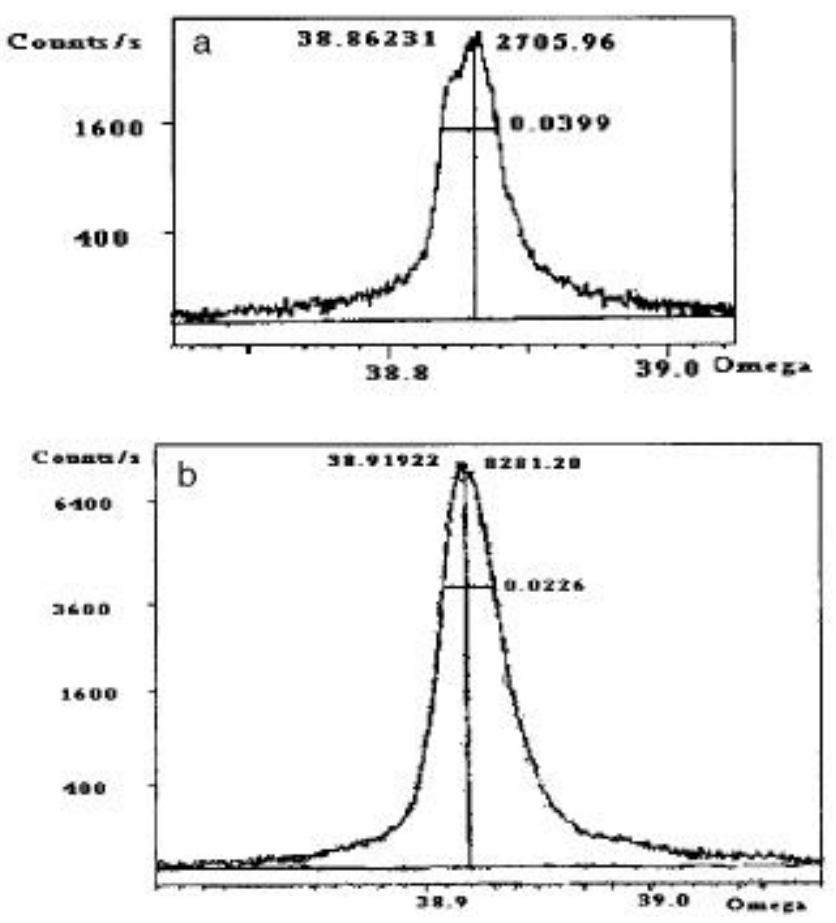

Figure 8. X-ray rocking curve a. before annealing and b. after annealing. 


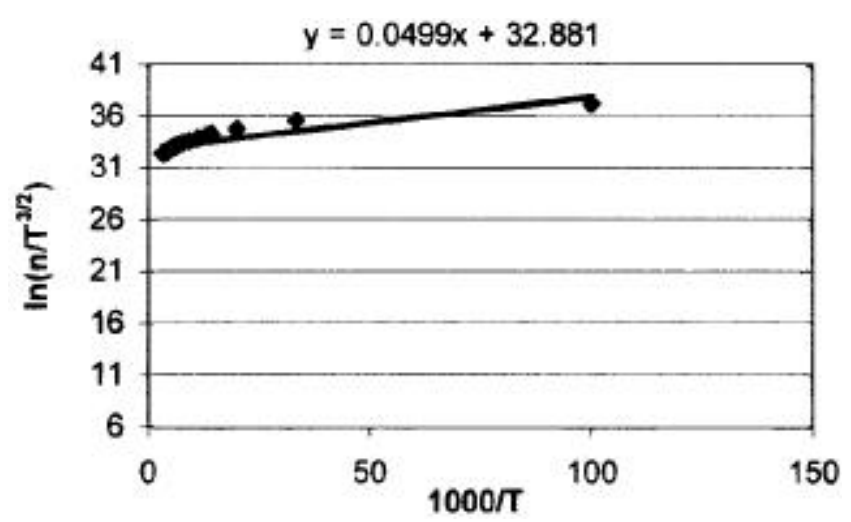

Figure 9. Variable temperature Hall measurement on $n$-type MCT film.

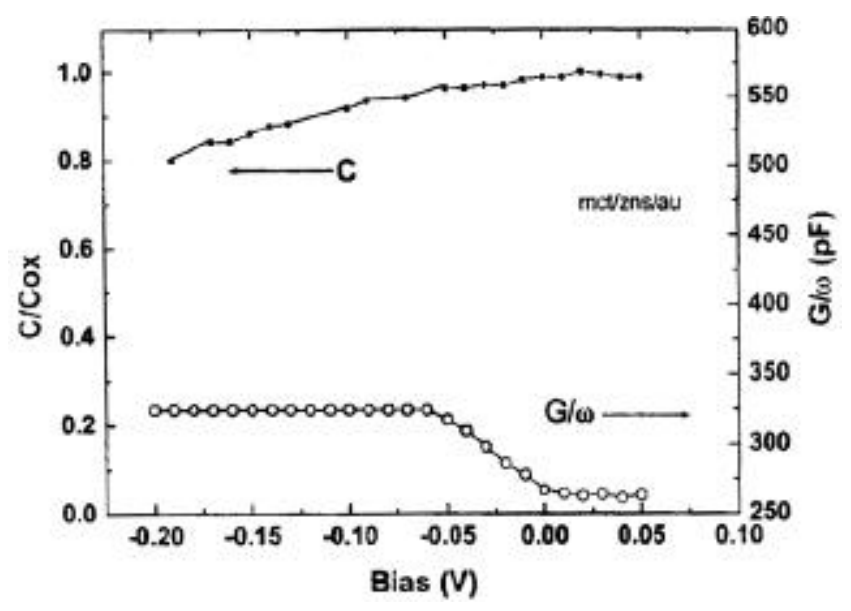

Figure 10. Capacitance-voltage $(C-V)$ and conductancevoltage $(G-V)$ measurements on MCT film.

range $200-100 \mathrm{mV}$ and $1 \mathrm{MHz}$ frequency. Also the conductance-voltage $(G-V)$ measurements were carried out. The results are presented for $x=0.2 n$-type MCT film in figure 10. As shown in the figure, the conductance curve flattens in the positive voltage range signifying the high frequency performance of the fabricated MIS diodes. The interface states $\left(Q_{\mathrm{f}}\right)$ were calculated from the $C-V$ measurements to be $\sim 2 \times 10^{11} \mathrm{~cm}^{-2}$.

\section{Conclusions}

A new technique called asymmetric vapour phase epitaxy (ASVPE) has been developed to carry out isothermal VPE growth experiments of MCT epitaxial films on CZT/CdTe substrates. This technique solves the problems of nonuniform vapour flux density available at the substrate and the vapour attack on the substrate surface during growth. Dislocation multiplication reduction (DMR) process has been successfully employed to reduce the defect enhancement during the annealing process. Low activation energy values obtained on $n$-type layers suggested that these layers are not compensated by impurities. The MIS diodes fabricated of the grown MCT films showed low interface state density and high frequency performance.

\section{Acknowledgement}

We thank Dr S C Gupta for useful technical discussions.

\section{References}

Adamiec K and Miroslaw G 1998 Proc. SPIE 299934

Bailly F, Svob L, Cohen-Solal G and Triboulet R 1975 J. Appl. Phys. 464244

Bagai R K, Meenakshi Srivastava, Kailash Sharma and Borle W N 1991 J. Cryst. Growth 112402

Becla P, Lagowski J, Gatos H G and Jedral L 1982a J. Electrochem. Soc. 1292855

Becla P, Lagowski J and Gatos H C 1982b J. Electrochem. Soc. 1291103

Bube R H 1960 in Photoconductivity of solids (New York: Wiley)

Chandra D, Tregilgas J H and Goodwin M W $1991 \mathrm{~J}$. Vac. Sci. Technol. B9 1852

Elliot T 1994 in Properties of narrow gap cadmium-based compounds (ed.) P Capper (UK: Inspec. Publ.) p. 1

Fleming J G and Stevanson D A 1987 J. Crystal Growth 82621

Hansen G L, Schmidt J L and Casselman T N 1982 J. Appl. Phys. 537099

Lu P Y, Wang C H, Williams, Chu S N G and Stiles M 1983 Appl. Phys. Lett. 491372

Norton P W and Erwin A P 1989 J. Vac. Sci. Technol. A7 503

Piotrowski J and Nowak Z 1988 Thin Solid Films 161157

Piotrowski J, Djuric Z, Galus W, Jovic V, Grudzien M, Djinovic Z and Nowak Z 1987 J. Cryst. Growth 83122

Schaake H F and Tregilgas J H 1983 J. Electron. Mater. 12931

Shin S H and Pasko J G 1984 Appl. Phys. Lett. 44423

Takigawa H, Yoshikawa M and Maekawa T 1988 J. Cryst. Growth 86446

Tufte O N and Stelzer E L 1969 J. Appl. Phys. 404559 